\title{
MODIFICATION EXPÉRIMENTALE DE L'APPARITION ET DE L'ÉVOLUTION DE LA PROPHASE MÉIOTIQUE DANS L'OVAIRE D'EMBRYON DE BREBIS
}

\author{
P. MAULÉON \\ Station de Physiologie de la Reproduction, I. N. R. A., \\ B. P. 1, Nouzilly, 37380 Monnaie (France)
}

\section{RÉSUMÉ}

L'apparition de la prophase méiotique dans les cellules germinales d'embryon de brebis peut être supprimée pendant 8 à 12 jours par la mise en culture de la gonade. Il en est ainsi si l'ovaire est prélevé avant le $50^{\mathbf{e}}$ jour, c'est-à-dire avant l'âge où la prophase méiotique commence chez cette espèce. De rares figures leptotènes ou zygotènes anormales sont parfois visibles ; mais aucun stade plus avancé de la méiose n'a jamais été observé dans ces conditions de prélèvement. Les ovogonies qui restent après Io- 2 jours de culture n'ont pas perdu leur capacité à entrer en méiose lorsque l'ovaire mis en culture est greffé chez un embryon de 57 jours.

Si la prophase méiotique a déjà commencé lorsque le prélèvement pour la mise en culture a lieu, le processus se poursuit. Cependant, l'évolution de la prophase méiotique subit des modifications quantitatives qui vont dans le sens d'une apparition et d'une évolution rares des premiers stades de la prophase méiotique.

L'effet de l'ablation hypophysaire (hypophysectomie ou décapitation) est celle d'une apparition retardée de la prophase méiotique sans doute due au stress opératoire. Le processus se déroule ensuite normalement. discutée.

La vraisemblance d'un " déterminant méiotique " et de son environnement favorable est

L'importance biologique de la prophase méiotique est telle qu'elle a fait l'objet de nombreuses descriptions. Cet événement se situe dans les cellules germinales après de longues séries de divisions mitotiques aussi bien dans les gonades mâles que femelles. Mais ce changement de comportement mitotique en comportement méiotique des cellules germinales n'est pas déterminé au même moment dans la gonade mâle et dans la gonade femelle. La chronologie du déroulement de la méiose apparaît caractéristique du sexe et semble dépendre uniquement des chromosomes sexuels.

Lorsqu'il y a stimulation ou levée d'inhibition les cellules germinales entrent en prophase méiotique et il y a peu d'exemples où ce processus ait été arrêté expérimentalement, sauf en augmentant la température de cultures in vitro de microsporo- 
cytes (STERN et HoTTA, I967). Par contre, en agissant de façon précise au niveau des synthèses des acides nucléiques ou des protéines qui se produisent au début de cette période, il est possible de changer le comportement des chromosomes au cours de leur accouplement au stade zygotène ou au cours de la réalisation des chiasmata (Ito, Hotta et Stern, I967 ; Parchman et SterRn, I969, Roth et Parchman, I97I).

L'étude des chimères expérimentales renforce l'idée de l'importance de la constitutioñ génétique propre des cellules germinales dans la détermination du moment de leur entrée en méiose (Mystowska et Tartowskr, I970; MacLaren, Chandley et KOFMAN-AI,FARO, I972). Mais les résultats de cette étude obligent à admettre qu'un environnement somatique défavorable puisse être hostile au développement des cellules germinales méiotiques au-delà du stade pachytène ou responsable de la faible proportion de ces cellules méiotiques avant la naissance dans les testicules $x x / x y$. Contrairement à ces recherches, des études sur des taureaux et des mâles ouistitis, chimères du point de vue chromosomes sexuels car nés de gestations gémellaires hétérosexuelles, semblent indiquer que le déroulement de la méiose des cellules $x x$ puisse être aussi sous contrôle d'un environnement (TEPL,ITZ et al., I967;BENIRSCHKE et BROWNHIL I I 663). Il est donc difficile de concilier de tels faits et l'on ne pourra apporter que des spéculations sur les mécanismes dirigeant la méiose dans les cellules $x x$ tant que de plus nombreuses expériences n'auront pas été mises en place pour en modifier son cours.

Deux conditions susceptibles de modifier l'environnement des ovaires en formation, 1'hypophysectomie des embryons et la culture in vitro de la gonade embryonnaire, ont été créées afin de voir comment apparaissait et évoluait la prophase méiotique dans les cellules germinales.

\title{
MATÉRIEL ET MÉTHODES
}

\author{
tal. \\ Des embryons de brebis de race Ile-de-France, d'âge connu, ont servi de matériel expérimen-
}

\section{A. - Technique de culture in vitro d'ovaives embryonnaires}

La technique de culture organotypique utilisée est voisine de celle de FaINSTATr (I968), et le milieu de culture est comparable à celui de Thibault et GtrRARD (I970). Une concentration en oxygène de $55 \mathrm{p}$. Ioo est assurée dans la chambre de culture. Les ovaires sont posés sur un fragment de millipore a vant d'être placés sur grille ce qui facilite leur récupération à la fin du temps de culture en évitant leur développement entre les mailles de la grille. La rapidité de prélèvement, la réduction des manipulations de l'organe à un transfert sur un nouveau milieu permettent d'obtenir d'excellentes cultures pendant I 2 jours, dans lesquelles la population de cellules germinales est peu modifiée. La proportion de cellules germinales dans la zone corticale est de 20,8 p. I00 dans l'ovaire de 47 jours cultivé in vitro pendant I 2 jours et respectivement de I 2,9 p. Ioo et 22,9 p. Ioo par rapport au nombre total de cellules dans les ovaires témoins de 50 jours et de 60 jours.

\section{B. - Techniques chirurgicales}

a) Ablation de l'hypophyse chez l'embryon de brebis.

L'hypophysectomie peut être réalisée avec succès chez les embryons de brebis âgés de 55 à 60 jours par voie sous orbitaire avec une technique voisine de celle utilisée chez le rat prépubère par voie auriculaire (FALCont et Rossi, I964). La nécessité d'effectuer cette ablation chez de jeunes embryons de 47 jours a conduit à la mise au point d'une hypophysectomie par voie parapha- 
ryngée. Le souci de supprimer les risques d'enlèvement partiel de l'hypophyse a fait comparer les résultats de cette technique à ceux de la décapitation déjà très utilisée chez les embryons de lapin et de rat par JosT (r947).

Les taux de réussite de ces différentes techniques sont données dans le tableau $r$.

\section{TABLEAU I}

Taux de réussite des différentes techniques d'ablation de l'hypophyse utilisées chez les ovins

\begin{tabular}{|c|c|c|c|c|c|c|c|}
\hline \multirow{2}{*}{ Technique } & \multirow{2}{*}{$\begin{array}{l}\text { Age des } \\
\text { embryons } \\
\text { (j) }\end{array}$} & \multirow{2}{*}{$\begin{array}{c}\text { Nombre } \\
\text { d'embryons } \\
\text { opérés }\end{array}$} & \multicolumn{2}{|c|}{$\begin{array}{l}\text { Taux de survie } \\
\left(\mathrm{T}_{s}\right) \text { pendant }\end{array}$} & \multirow{2}{*}{$\begin{array}{c}\text { Taux } \\
\text { d'hypophysectomie } \\
\text { totale }\left(\mathrm{T}_{t}\right) \\
(\%)\end{array}$} & \multicolumn{2}{|c|}{$\begin{array}{l}\text { Taux de réussite } \\
\qquad \mathrm{T}_{8} \times \mathrm{T}_{t}\end{array}$} \\
\hline & & & $\begin{array}{c}<8 j \\
(\%)\end{array}$ & $\begin{array}{l}>8 \mathrm{j} \\
(\%)\end{array}$ & & $\begin{array}{c}<8 j \\
(\%)\end{array}$ & $\begin{array}{r}>8 j \\
(\%)\end{array}$ \\
\hline $\begin{array}{l}\text { Hypophysectomie } \\
\text { par voie } \\
\text { sous-orbitaire }\end{array}$ & $55-60$ & 35 & & 80 & 58 & & 46,4 \\
\hline $\begin{array}{c}\text { Par voie } \\
\text { parapharyngée }\end{array}$ & $47-52$ & 62 & 42,4 & 31,0 & 100 & 42,4 & 31,0 \\
\hline Décapitation & $47-65$ & 79 & 27,7 & 13,2 & 100 & 27,7 & 13,2 \\
\hline
\end{tabular}

Critères de survie : croissance du fœetus, battements cardiaques, circulation ombilicale normale.

La planche photographique (I) résume les différentes phases opératoires de l'hypophysectomie par voie parapharyngée qui apparaît comme une miniaturisation de celle utilisée chez l'agnelle ou la brebis (DENAMUR et MAULEON, I963). L'originalité principale consiste en l'extériorisation du fœtus pendant un temps maximum de une demi-heure. Ce laps de temps permet d'autres techniques opératoires chez les embryons de brebis : décapitations, ovariectomies et greffes d'ovaire.

La décapitation a été faite par enlèvement de la partie crânienne située au-dessus de la mâchoire supérieure après ligature des artères carotidiennes et coagulation des artères vertébrales. Les échecs proviennent le plus fréquemment d'une mauvaise hémostase de ces vaisseaux. Lorsqu'une compression importante de la trachée est provoquée par une deuxième ligature sousmaxillaire afin d'améliorer cette hémostase, un œdème important et une ascite sévère due à l'augmentation du volume pulmonaire et à un engorgement sanguin hépatique apparaissent alors comme l'a montré BeRTON (1969).

\section{b) Greffe des ovaires cultivés in vitro chez les embryons hôtes de 56-57 jours.}

Les deux premières phases opératoires sont semblables à celles de 1'hypophysectomie par voie parapharyngée. La castration des femelles est opérée par le flanc ; le greffon est fixé au niveau du ligament large ou du mésonéphros avec de très fines agrafes de platine de $4 / 100 \mathrm{de} \mathrm{mm}$. Le flanc est ensuite refermé en trois points avec des fils de soie (ooo.000). Des pertes de greffon peuvent se produire si cette fermeture aboutit à un déplacement du greffon de son lieu de fixation. Les résultats opératoires sont donnés dans le tableau 5.

\section{C. - Technique d'analyse des ovaires embryonnaires}

Une étude histologique a été faite après réaction nucléaire de Feulgen. Les stades de la prophase méiotique ont été identifiés selon des critères classiques de morphologie nucléaire (MAULÉoN, 1969) et le stade ultime d'avancement de la prophase méiotique a été recherché systématiquement dans les coupes sériées de la gonade. 
Deux critères quantitatifs ont permis d'apprécier l'apparition et le degré d'évolution de cette différenciation du noyau : le p. I oo de cellules en prophase méiotique par rapport au nombre total de cellules germinales et le rapport du nombre de stades leptotène + zygotène au nombre de stades pachytène + diplotène.

Ces pourcentages ont été déterminés après comptages d'au moins 500 cellules germinales de différents types nucléaires se trouvant dans 36 champs microscopiques distribués dans 3 coupes les plus médianes possibles, appartenant à quatre régions diamétralement opposées représentant toute l'épaisseur du cortex pour une coupe donnée.

Cet échantillonnage orienté est imposé par la différenciation centripète des cellules germinales dans le cortex, différenciation responsable d'une hétérogénéité de distribution de ces types cellulaires.

\section{RÉSULTATS}

\section{A. - Cultures organotypiques d'ovaires d'embryon de brebis}

L'âge de l'embryon au moment du prélèvement de l'ovaire pour sa mise en culture influence de façon très marquée le déroulement de l'ovogenèse dans ces gonades comme nous l'avons signalé dans une courte note publiée précédemment (Mauléon et Thibault, I97I).

Si l'ovaire est prélevé avant le 50e jour c'est-à-dire avant 1'apparition normale

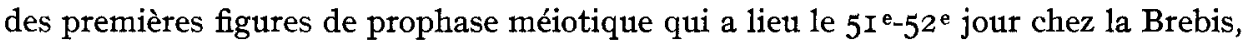
il n'a été trouvé, après 8 à I 2 jours de culture que des ovogonies. Elles sont souvent en activité mitotique. Un faible taux de figures nucléaires ressemblant à un stade leptotène mais présentant plutôt des arrangements nucléaires atypiques de la prophase méiotique peut s'y trouver (planche photographique II). Il n'a jamais été observé, sur plus de 50 ovaires mis en culture, dans ces conditions de prélèvement, de stade pachytène ou diplotène. Ces stades sont pourtant fréquents (les $3 / 5$ des cellules en prophase méiotique) dans un ovaire normal d'embryon de 60 jours c'est-à-dire de même âge.

Quantitativement, ces figures de type leptotène ou ces prophases atypiques sont rares (au plus ro,4 p. Ioo) alors que dans un ovaire normal de même âge $\left(60^{e}\right.$ jour) plus de $40 \mathrm{p}$. Ioo des cellules germinales sont différenciées en prophase méiotique. Dans les ovaires in vitro, les figures de début de méiose augmentent avec le temps de culture donc, avec l'âge de l'ovaire ainsi qu'avec l'âge de l'embryon au moment du prélèvement (tabl. 2).

Si l'ovaire est prélevé après le 50e jour, tous les stades de la prophase méiotique jusqu'au stade diplotène sont trouvés dans l'ovaire mis en culture. Les stades de la prophase méiotique semblent morphologiquement normaux (planche photographique III).

Toutefois, le pourcentage de cellules en prophase méiotique après Io-I2 jours de culture d'un ovaire prélevé au $55^{-56}$ e jour est anormalement bas $(24,4 \mathrm{p}$. Ioo v. s. 65-75 p. Ioo dans un ovaire témoin de 65-68 jours) (tabl. 2). Mais surtout le rapport des stades leptotène + zygotène sur pachytène + diplotène est plus faible que normalement dans un ovaire de cet âge $(0,42$ v. s. 0,67$)$, les stades du début de la méiose étant moins nombreux. 
TABLEAU 2

Apparition et évolution de la prophase méiotique dans des ovaires embryonnaires de brebis après culture in vitro en relation avec l'âge de l'embryon

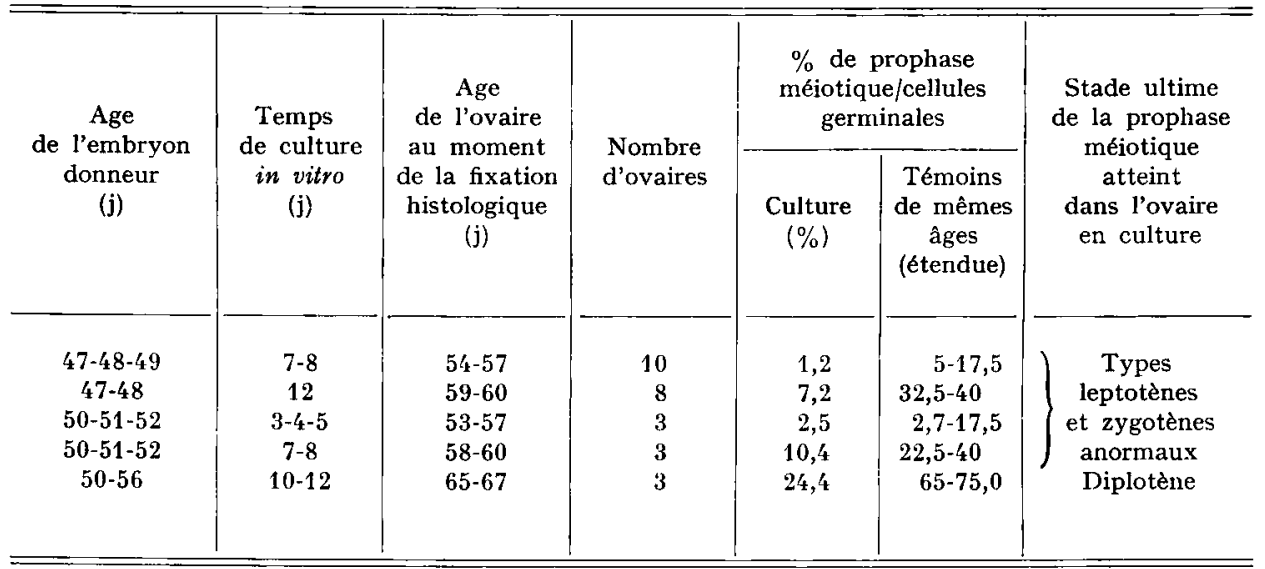

\section{B. - Hypophysectomie des embryons de Brebis. Action in vitro des hormones gonadotropes}

Lorsque l'hypophysectomie ou la décapitation de l'embryon est faite à un âge où la prophase méiotique a débuté, il n'apparaît pas qualitativement de différence dans l'évolution de la prophase méiotique.

Lorsque cette suppression de l'hypophyse est faite par hypophysectomie parapharyngée ou décapitation chez des embryons plus jeunes entre le 47 et le $5^{\mathrm{r}}$ jour d'âge, les premières figures leptotènes n'apparaissent pas avant le $55^{\mathrm{e}}$ jour. Elles ne sont alors que très rares $(0,5$ p. I00 v. s. 7,2 p. Ioo dans l'ovaire témoin de 55 jours). Mais si les ovaires de l'animal opéré à 47 jours (hypophysectomisé ou décapité) ne sont prélevés que 8-Io jours voire 20 ou 30 jours plus tard, qualitativement la prophase méiotique semble s'être déroulée normalement puisque tous les stades de la méiose (planches photographiques II et III) peuvent être vus dans l'ovaire. En particulier, il existe une très grande similitude entre l'édification des follicules primordiaux d'un ovaire d'embryon de 77 jours décapité depuis 30 jours et cette même phase de l'ovogenèse chez l'embryon témoin de 74 jours, c'est-à-dire d'âge très voisin (planche photographique IV).

Quantitativement, par contre, il est certain que le déroulement de la prophase méiotique a été perturbé. Après II jours de suppression de 1'hypophyse et quelle que soit la technique, le $p$. Ioo de cellules germinales en prophase méiotique est 2 fois et demie plus faible à 60 jours (I5,I p. roo v. s. 4I,7 p. IOO). Mais aussi, le rapport stades leptotène + zygotène sur pachytène + diplotène est beaucoup plus élevé $(4,5$ v. s. 0,67$)$ ce qui signifie que les stades du début de la prophase méiotique sont plus nombreux (tab1. 3).

L'action possible des hormones gonadotropes sur l'apparition de la prophase méiotique a été abordé également en cherchant à provoquer l'apparition de figures 
P. MAULÉON

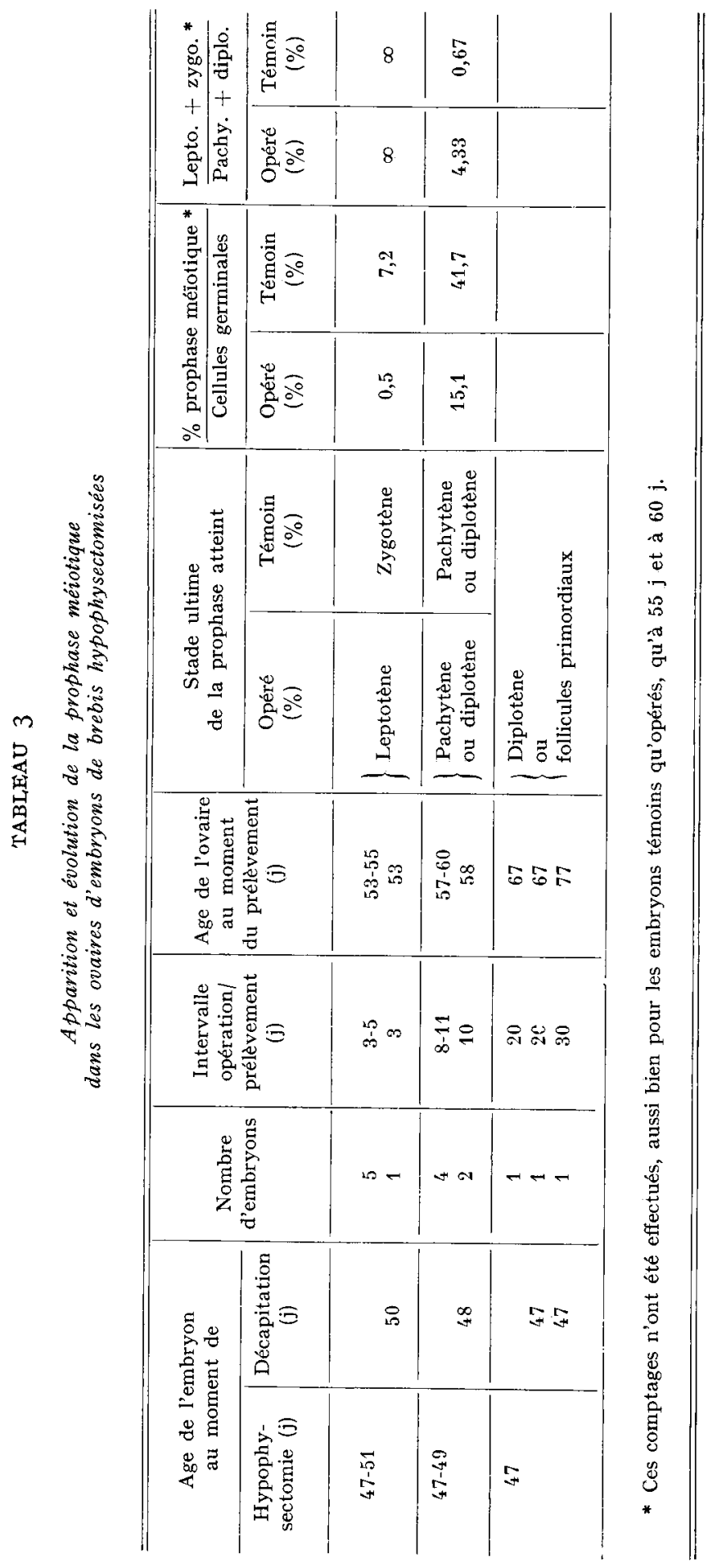


de prophase méiotique dans des ovaires d'embryons de 49 jours mis en culture pendant 6 à 8 jours (tabl. 4). Quelle que soit la méthode d'addition de ces hormones hypophysaires utilisée, l'aspect des ovaires placés en culture in vitro n'a pas été modifié.

\section{TABLEAU 4}

Diverses méthodes d'addition d'hormones gonadotropes au milieu de culture des ovaires embryonnaires de brebis de 49 jours

(Temps de culture : 6-8 jours)

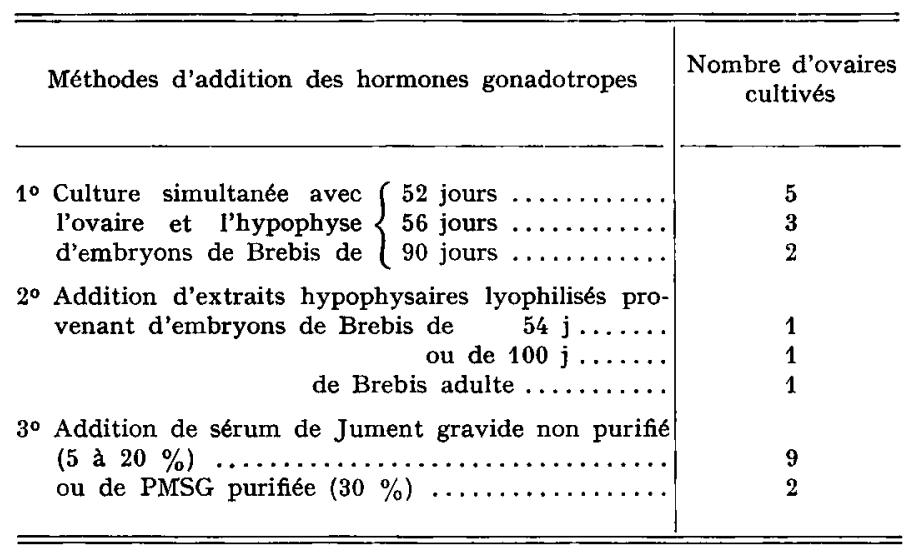

\section{C. - Greffe d'ovaires d'embryons de Brebis cultivés in vitro}

En dépit de l'aspect favorable des cultures d'ovaires, les cellules germinales présentes après 8-I2 jours de séjour in vitro sont susceptibles d'avoir perdu la capacité d'entrer en méiose. Pour tester cette éventualité, de tels ovaires ont été greffés dans la région rénale d'embryons hôtes de 56-57 jours c'est-à-dire à un âge où la prophase méiotique est très active.

La prophase méiotique apparaît et évolue jusqu'au stade diplotène dans ces cellules germinales encore ovogonies au moment où le greffon a été placé dans l'hôte. Mais cette apparition et a fortiori cette évolution ne sont pas immédiates. Après 6 jours de séjour du greffon chez l'hôte nous n'avons trouvé qu'une forte activité mitotique des ovogonies. Les figures de mitoses ont un aspect à chromosomes dispersés caractéristique des dernières divisions ovogoniales se produisant juste avant la méiose. Par contre, après I4 jours ou 20 jours de séjour chez l'embryon hôte, l'évolution de la prophase méiotique a été complète (tab1. 5). Normalement, il faut de l'ordre de 7 à 8 jours pour que le stade diplotène soit atteint chez 1'embryon de Brebis normal (MAULÉon, I96I), ce qui est compatible avec un démarrage de la prophase méiotique après 5 ou 6 jours de greffe et la présence de stades diplotène après $\mathrm{I} 4$ jours de séjour chez l'hôte.

Après I4 jours de greffe, l'ovaire prélevé initialement à 47 jours et cultivé in vitro pendant 9 jours n'a pas la structure microscopique d'un ovaire témoin d'âge voisin de $7^{0}$ jours (planche photographique IV). A cet âge, les cellules en prophase méiotique représentent les $3 / 4$ de la population des cellules germinales et les stades avancés constituent les $7 / 8$ de ces ovocytes. 


\section{TABLEAU 5}

Résultats des greffes chez des embryons de brebis de 56-57 jours d'ovaires embryonnaires de 47-48 jours cultivés in vitro pendant 9-10 jours

\begin{tabular}{c|c|c|c}
\hline $\begin{array}{c}\text { Temps de séjour } \\
\text { des ovaires « cultivés " } \\
\text { chez les embryons } \\
\text { " hôte "(j) }\end{array}$ & $\begin{array}{c}\text { Survie } \\
\text { des embryons } \\
\text { " hôte " }\end{array}$ & $\begin{array}{c}\text { Récupération } \\
\text { des greffons } \\
\text { ovariens }\end{array}$ & $\begin{array}{c}\text { Présence de } \\
\text { figures méiotiques } \\
\text { (stade ultime) }\end{array}$ \\
\hline 6 & $4 / 4$ & $4 / 4$ & \\
14 & $3 / 3$ & $2 / 3$ & $\begin{array}{c}\text { Néant } \\
\text { (mitoses goniales } \\
\text { dispersées) } \\
\text { Diplotène } \\
\text { Diplotène }\end{array}$ \\
\hline \hline
\end{tabular}

Dans ce même greffon de I4 jours, les deux paramètres habituels sont respectivement 32,6 p. Ioo et $0,9 \mathrm{I}$ c'est-à-dire qu'ils correspondent approximativement à l'état d'avancement de l'ovogenèse dans un ovaire de 58-59 jours (tab1. 6). La confusion possible avec un fragment d'ovaire laissé chez l'embryon-hôte au moment de la castration est donc impossible. L'évolution de la prophase méiotique dans le greffon traduit bien que cette différenciation a été bloquée pendant les 9 jours de culture.

\section{TABLEAU 6}

Evolution de la prophase méiotique dans les ovaires embryonnaires de brebis cultivés in vitro puis greffés chez des hôtes de 57 jours (p.c.)

\begin{tabular}{|c|c|c|}
\hline Type d'ovaire & $\frac{\% \text { prophase méiotique }}{\text { Cellules germinales }}$ & $\frac{\text { Leptotène }+ \text { zygotène }}{\text { Pachytène }+ \text { diplotène }}$ \\
\hline $\begin{array}{c}48 \mathrm{j}+9 \mathrm{j} \text { (culture) } \\
48 \mathrm{j}+9 \mathrm{j} \text { (culture) } \\
\text { et }+14 \mathrm{j} \text { (greffe) } \\
60 \mathrm{j} \text { (témoin) } \\
74 \mathrm{j} \text { (témoin) }\end{array}$ & $\begin{array}{r}1,2 \\
32,6 \\
41,7 \\
72,6\end{array}$ & $\begin{array}{c}\infty \\
0,91 \\
0,67 \\
0,14\end{array}$ \\
\hline
\end{tabular}

\section{DISCUSSION}

Les conditions expérimentales utilisées permettent de modifier l'apparition et l'évolution de la prophase méiotique dans l'ovaire d'embryon. Toutefois, ces changements ne sont visibles de façon tranchée que si ces conditions sont crées avant le $5^{0}$ jour d'âge. Nous avons résumé l'ensemble des modifications provoquées dans un diagramme. 
Des expériences de mise en culture in vitro d'ovaires embryonnaires ont pourtant été réalisées précédemment sans que les auteurs n'aient seulement émis l'hypothèse de la possibilité de telles modifications du déroulement de l'ovogenèse.

"Le processus entier de l'ovogenèse peut avoir lieu in vitro dans des conditions de culture appropriées "(MARTINOVITCH, I938).

Cette idée exprimée par MARTINoviTch (I938) est encore couramment admise et d'autres auteurs pensent l'avoir confirmée chez la Ratte (Bousquer, Ig67) chez la Souris (SAlzGEBER, I962), chez l'Homme (Bl,ANDAU, I969), chez les Oiseaux (WOLFF et HAFFEN, I952; HAFFEN, I964; NARBAITZ et ADLER, I966).

Certes, lorsque l'ovaire est prélevé après le $5^{\circ}$ jour et si nous ne cherchons pas à apprécier quantitativement l'évolution de la prophase méiotique nous pouvons dire que les observations des précédents auteurs sont confirmées. Mais dans ces expériences de cultures in vitro d'ovaires embryonnaires, rares ont été les cas où la gonade a été retirée de 1'embryon à un âge où la prophase méiotique n'avait pas débuté. Lorsque cela s'est prođuit, souvent il n'a pas été montré d'évolution particulière d'un prélèvement d'un âge donné mais seulement une analyse globale des résultats de culture in vitro des ovaires de différents âges.

Cependant, SALZGEBER (I96I) a signalé que la culture de gonade indifférenciée sexuellement d'embryon de Souris, c'est-à-dire juste avant l'apparition de la prophase méiotique dans l'ovaire de cette espèce, était difficile voire impossible. Cela signifie peut-être qu'elle n'obtenait pas de différenciation des ovogonies en ovocytes. Enfin, une relation entre le poids des embryons de Souris où l'ovaire est prélevé et la possibilité d'obtenir des ovocytes évolués jusqu'au stade follicule primordial a été rapportée récemment par OGAWA (I968); le poids de $200 \mathrm{mg}$ des embryons constitue une limite dans la maturation de l'ovaire de l'embryon avant laquelle il n'est obtenu que des ovogonies. Il est toutefois difficile en microscopie à contraste de phase de reconnaitre, comme le fait OGAWA, ovocytes et ovogonies. BLANDAU (I969) utilisant une technique identique devait fixer les fragments d'ovaires humains cultivés in vitro pour identifier les ovocytes qui n'avaient pas encore augmenté suffisamment de diamètre pour être reconnaissables.

Suivant l'âge de l'embryon au moment du prélèvement de l'ovaire mis en culture in vitro les ovogonies se différencient ou non en ovocytes. Une interprétation possible de ce résultat est de dire que la prophase méiotique peut se poursuivre dans les cellules ayant déjà reçu une induction et qu'aucune ovogonie ne 1'a subie si le prélèvement est suffisamment précoce.

La critique la plus courante formulée à l'encontre d'un résultat négatif obtenu in vitro est celle des modifications trop profondes de l'environnement de l'organe. Certes, la prophase méiotique débute dans quelques cellules germinales sous des formes atypiques leptotène et surtout zygotène; ceci est en faveur d'une thèse de perturbations anormales. Mais si ces stades existent au moment de la mise en culture, ils sont capables d'évoluer normalement en pachytène et diplotène. Les cellules germinales se divisent in vitro. Elles y synthétisent ADN et protéines et y trouvent les autres conditions qui permettent aux processus déterminant la prophase mitotique de se réaliser. Par contre, les processus qui modifient le changement de comportement des chromosomes au cours de la prophase méiotique ne se développent pas.

L'existence d'un inducteur de la méiose n'a jusqu'ici été montré que dans le cas 
de la maturation des ovocytes des Étoiles de mer ; la I-méthyladénine agit au moment de la reprise de la méiose sur la rupture de la vésicule germinative (KANATANI et ShIRAI, I967, I97I; STEVENS, I970 ; SchumTz, I970). Cette action est bien différente de celle de la détermination des cellules germinales à débuter leur différenciation méiotique. A ce moment, le premier événement identifiable est une suppression sélective de $0,3 \mathrm{p}$. Ioo de la synthèse de l'ADN à la fin de la prophase préméiotique (STERN et HotTA, I969). Mais ce retard dans la synthèse de 1'ADN n'est pas suffisant pour déterminer l'entrée de la cellule en méiose bien que les cellules germinales aient perdu au cours de la phase $G_{2}$ qui suit cette synthèse partielle de l'ADN leur capacité à se diviser de façon équationnelle. Rien n'est connu sur la nature de cette détermination. Par contre, à la fin de cette période et tout au début du stade leptotène va se produire une synthèse protéique essentielle (STERN et HoTTA, I969; HEcht et STERN, I97I ; Ho'TTA et STERN, I97I). Elle permet la réalisation de l'accouplement des chromosomes du complexe synaptinemal au niveau des régions d'ADN à une seule bande (HowEI, et STERN, I97I). Cette "protéine de liaison " de 1'ADN a été isolée dans les cellules en méiose du Lilium, mais n'a pu l'être à partir des cellules somatiques de ce même végétal. Elle est synthétisée de novo à un moment précis de la prophase méiotique. Sa valeur fonctionnelle est générale puisqu'elle a été purifiée également à partir des spermatocytes de mammifères (HOTTA et STERN, I97I).

L'ensemble de ces données sur la physiologie de la méiose permet d'imaginer que des phénomènes d'inhibition ou de non stimulation puissent exister. Par exemple, si des échanges entre cellules somatiques ou cellules germinales sont rompus ce qui a lieu lorsque 1'architecture ovarienne en culture in vitro est trop modifiée ou si le milieu nutritif est inadéquat, l'induction peut être supprimée ou perturbée. L'existence de périodes de détermination de l'entrée en méiose et de périodes de provocation de formes atypiques permet de comprendre l'influence importante de l'âge de prélèvement de l'ovaire sur les résultats de la mise en culture in vitro. Mais le fait que les cellules après un temps de culture puissent retrouver, chez l'embryon et vraisemblablement - si les résultats préliminaires se confirment - seulement chez un embryon d'un âge donné, les conditions favorables au "déterminant méiotique ", suggère qu'un environnement, au sens le plus large, doit être créé.

La certitude d'une activité hormonale hypophysaire chez le fœetus (DuBors et MAULÉoN, I968) peut faire penser, par analogie avec la non apparition de la prophase méiotique chez le jeune mâle hypophysectomisé, à une régulation hormonale de ces phénomènes. Jusqu'ici, lorsque des embryons de mammifères ont été décapités, les gonades femelles n'ont pas été observées. Dans le cas des embryons de Brebis, la suppression de 1'hypophyse a été faite trop tard pour avoir une action de ce type (Lanman et Schafer, I968 ; Liggins, Kennedy et Holm, I967). Seul, Raynaud (I950) note une diminution du nombre des cellules germinales après hypophysectomies de jeunes souris femelles; mais, l'irradiation qui a servi à détruire l'hypophyse fotale peut fort bien en être responsable. L'effet de l'hypophysectomie, dans notre cas, apparaît comme une action provisoire. Un stress opératoire peut en être la cause. Une activité hormonale placentaire gonadotrope suggérée par VANKAMPEN et EIIIS (I972) chez la Brebis pourrait prendre le relai de 1'hypophyse fotale. Si l'on admet qu'une telle activité dépende du type de placentation, elle devrait être très faible chez les porcins. La décapitation des embryons du Porc au $42^{\mathrm{e}}$ jour, c'est-à-dire 
avant le début de la prophase méiotique dans les gonades, n'empêche pas que les ovaires prélevés II jours plus tard ne soient riches en tous stades de la prophase méiotique.

Les faits expérimentaux observés sont compatibles avec l'existence d'un déterminant méiotique. Les facteurs qui modifient son existence sont peu précisés au cours de ces expériences.

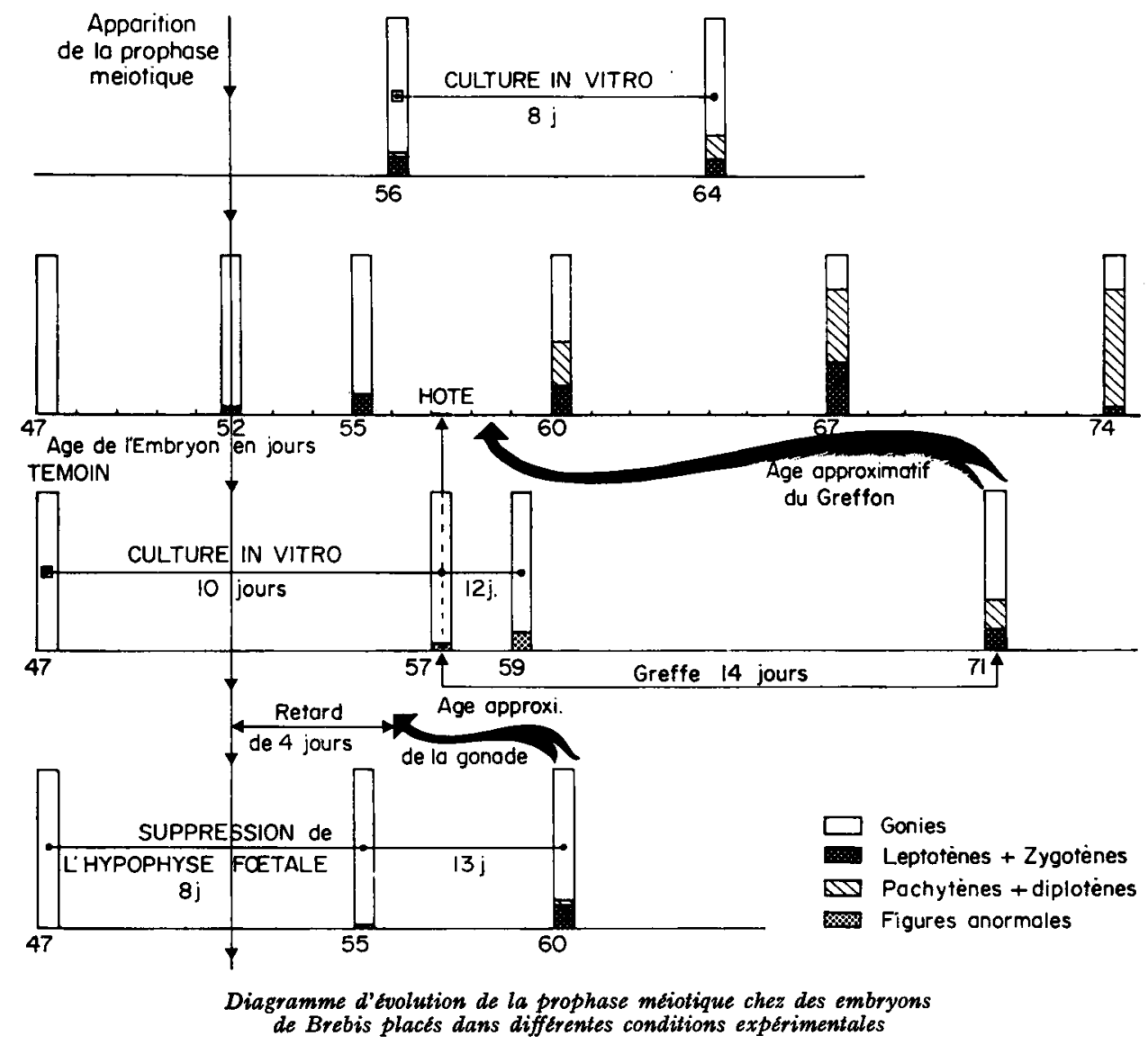

\section{REMERCIEMENTS}

Ce travail a reçu l'aide de la délégation à la Recherche scientifique et technique que nous remercions (contrat $\mathrm{n}^{0}$ 7 $\mathbf{1}-\mathbf{7}^{-3020}$ ). Nous exprimons notre gratitude à Mmes J. BEZARD, F. BERTHELOT et M. GERARD pour leur assistance technique efficace, et notre reconnaissance au professeur Thibault pour ses conseils et ses critiques. 


\title{
SUMMARY
}

\author{
EXPERIMENTAL AITERATIONS IN THE APPEARANCE AND EVOLUTION \\ OF MEIOTIC PROPHASE IN THE OVARY OF THE SHEEP FOETUS
}

The onset of meiotic prophase in the germ cells of sheep fotus is suspended by the culture in vitro of the gonad for 8 or $\mathbf{I} 2$ days, if the ovary is removed from the foetus before day 50, that is, before the age when meiotic prophase begins in this species. A few leptotene and abnormal zygotene can be found in serial sections, but more advanced stages are never seen in these conditions. The oogonia which remain at the end of the culture period do not loose the capacity to enter in meiosis when the ovary is grafted into a 57 day-old sheep fœtus.

If the meiotic prophase has already begun at the time of ovary removal, the process continues. However, its evolution undergoes some quantitative modifications measured by the percentage of meiotic stages in the germ cells and the ratio leptotene + zygotene on pachytene + diplotene in the oocytes. The low value of these relationships after ro days of culture indicates that in vitro. new waves of meiotic prophase do not appear. This confirms the first experiment and the impossibility of starting meiosis in vitro.

Hypophysectomy or decapitation delays the appearance of meiosis because of probable operative stress, but further development of oogenesis is qualitatively normal. However; the shift persists. The possibility of a "meiotic determinant " and its favorable environment are discussed.

\section{RÉFÉRENCES BIBLIOGRAPHIQUES}

Benirscike K., Brownhill L. E., I963. Heterosexual cells in testes of chimeric marmoset monkeys. Cytogenetics, 2, 331-34I.

Berton J.-P., I 969 . Effet de la ligature de la trachée chez le fœtus de mouton à la fin du Ier et au $2^{\text {e }}$ tiers de la gestation. Accumulation de liquide dans les ramifications bronchiques primitives et anarsaque fœeto-placentaire. Bull. ass. Anatomistes $L I V^{\text {e }}$ Congrès, Sofia, 145, 73-96.

BLANDAU R., I969. Observations on living oogonia and oocytes from human embryonic and fetal ovaries. Am.J. Obstet. Gynec., 104, 310-3I9.

Bousouet J., 1967. Culture organotypique de fragments d'ovaires de Ratte. Action de facteurs gonadotropes hypophysaires. C. $R$. Soc. Biol., 161, 778-782.

Denamur R., Mauléon P., 1963. Effet de l'hypophysectomie sur la morphologie et l'histologie du corps jaune des ovins. C. R. Acad. Sci., Paris, 257, 264-267.

Dubois M., Mauléon P., r969. Mise en évidence par immunofluorescence des cellules à activité gonadotrope LH dans l'hypophyse du fœetus de brebis. C. R. Acad. Sc., Paris, 269, 219-222.

FaINSTAtT T., r968. Organ culture of postnatal rat ovaries in chemically defined medium. Fertil. Steril., 19, 3 I7 $733^{8}$.

Falconi G., Rossi G.L. I964. Transauricular hypophysectomy in rats and mice Endocrinology, 74, 30I-303

HAFFEN K., 1964. Sur la culture in vitro des glandes génitales des embryons de caille (Coturnix Coturnix) obtention de la différenciation sexuelle normale et de l'intersexualité expérimentale des gonades explantées. C. R. Acad. Sci., Paris, 259, 882-884.

Hecht N. B., Stern H., 197I. A late replicating DNA protein complex from cells in meiotic prophase. Expl. Cell. Res., 69, т-го.

HotTA Y., Stern H., r971. Analysis of DNA synthesis during meiotic prophase in Lilium. J. Mol. Biol., 55, 337-355.

HоттA Y., SteRn H., x97I. Meiotic protein in spermatocytes of mammals. Nature, New Biol., 234, $83-86$.

HotTa Y., SteRn H., r97I. A DNA-binding protein in meiotic cells of Lilium. Devel. Biol., 26, 87-99.

Howell S. H., STERN H., r97I. The appearance of DNA breakage and repair activities in the synchronons meiotic cycle of Lilium. J. Mol. Biol., 55, 357-378.

Ito M., Hotta Y., Stern H., I967. Studies of meiosis in vitro. II. Effect of inhibiting DNA synthesis during meiotic prophase on chromosome structure and behavior. Develop. Biol., 6, 54-77.

Jost A., 1947. Expériences de décapitation de l'embryon de lapin. C. R. Acad. Sci., 225, 322. 
Kanatani H., SchiraI H., I967. In vitro production of meiosis inducing substance by nerve extract in ovary of starfish. Nature, 216, 284-286.

Kanatani H., Shirai H., I97I. Chemical structural requirements for induction of oocytes maturation and spawning in starfish. Development, growth and differentiation, 13, 53-64.

Lanman J. T., Schafer A., 1968. Gestational effects of fetal decapitation in sheep. Fertil. Steril., 19, $598-605$.

Liggins G. C., Kennedy P. C., Holm L. W., I967. Failure of initiation of parturition after electrocoagulation of the pituitary of the fetal lamb. Obstetrics, 98, 1080-1086.

Mclaren A., Chandley A. C., Kofman-Alfaro S., 1972. A study of meiotic germ cells in the gonads of fœtal mouse chimaeras. J. Embryol. exp. Morph., 27, 515-524.

Martinovitch P. N., I938. The development in vitro of the mammalian gonad ovary and ovogenesis. Proc. Roy. Soc., sér. B, 125, 232-249.

Mauléon P., r96r. Déroulement de l'ovogenèse comparée chez différents mammifères domestiques. Proc. IVth Congr. int. Reprod. anim., La Haye, 2, 348-354.

MAULÉon P., r969. Oogenesis and folliculogenesis. Reproduction in domestic animals (2nd éd.) chap. 7, éd. Cole et Cupps, Academic Press.

MaulÉon P., Thibault C., I97r. Evolution of oogenesis during in vitro culture of the ovaries of sheep embryos. Excerpta Medica VII e Congr. fertil. steril., Tokyo-Kyoto, I7-25 octobre I97I, série $n^{\circ} 234 a, 45$.

Mystkowska E. T., Tartowski A. K., 1970. Behavior of germ cells and sexual differenciation in late embryonic and early postnatal mouse chimeras. J. Embryol. exp. Morph., 28, 295-405.

Narbaitz R., AdLer R., r966. Germ cell differentiation in embryonic gonads cultured in heterosexual parabiotic pairs. Experientia, 22, 677-678.

OGawa W., r968. Studies on the ovogenesis of the mice embryos using tissue culture method. Jap. J. Fert. Steril., 13, 64-78.

Oнмо S., 1970. Morphological aspects of meiosis and their genetical significance. The human testis, Plenum Press, II5-I25.

Parchman L. G., Stern H., 1969. The inhibition of protein synthesis in meiotic cells and its effect on chromosome behavior. Chromosoma, 26, 298-3II.

Raynaud A., 1950. Recherches expérimentales sur le développement de l'appareil génital et le fonctionnement des glandes endocrines des fœetus de souris et de mulot. Archs Anat. Microsc. morph. exp., 39, $518-576$.

Roth T. F., Parchman L. G., I97r. Altération of meiotic chromosomal pairing and synaptonemal complexes by cycloheximide. Chromosoma (Berl.), 35, 9-27.

Salzgeber B., r962. Étude du développement de l'ovaire de souris greffé dans l'embryon de poulet après culture in vitro. Archs. Anat. Micr. Morph. exp., 51, 1-10.

Schuetz A. W, I970. Effects of I-methyladenosine on isolated gonads and oocytes of the starfish; evidence for an ovarian wall nucleosidase. Biol. Bull., 139, 435.

Stern H., Hotra Y., r967. Chromosome behavior during development of meiotic tissue. The control of nuclear activity Edited by L. Golstein, Prentice Hall, Englewood Cliffs, N. J., 47-76.

Stern H., Hotta Y., 1969. DNA synthesis in relation to chromosome pairing and chiasma formation. Genetics, suppl., 61, 27-39.

Stevens M., I970. Procedure for induction of spawning and meiotic maturation of starfish oocytes by treatment with I-methyladenine. Expl Cell Res., 58, 482-484.

Teplitz R. L., Moon Y. S., BasRuR P. K., I967. Further studies of chimerism in heterosexual cattle twins. Chromosoma, 22, 202-209.

Thibault C., GÉrard M., r970. Facteur cytoplasmique nécessaire à la formation du pronucleus mâle dans l'ovocyte de lapine. C. R. Acad. Sci., Paris, 270, 2025-2026.

VAn Kampen K. R., Ellis L. C., r972. Prolonged gestation in ewes ingesting Veratrum californicum: morphological changes and steroid biosynthesis in the endocrine organs of cyclopic lambs. $J$. Endocr., 52, 549-560.

WolfF Et., Haffen K., I952. Sur le développement et la différenciation sexuelle des gonades embryonnaires d'oiseau en culture in vitro. J. exp. Zool., 119, $38 \mathrm{Il}$. 


\section{LEGENDE DES PLANCHES}

Stades de la prophase méiotique

Figures normales

$>$ Leptotène

伃 Zygotène

- Pachytène

$\star$ Diplotène
Figures anormales

Leptotène

Zygotène

\section{PLANCHE I}

Description de la technique d'hypophysectomie par voie parapharyngée. Embryon de Brebis de 47-52 jours

FIG. I

Suspension de l'utérus. donaire.

Ouverture médiane et longitudinale dans l'espace acotyléFIG. 2

Ouverture de l'amnio-chorion, bords retenus par des clamps rejetés sur l'utérus.

FrG. 3

Embryon sorti de la poche amniotique placé dans un "berceau " à distance préréglée d'une loupe chirurgicale. Humidification, température, aseptie contrôlées.

\section{FIG. 4}

Fixation de la tête par un fil. tendu.

Relation mère-fœetus maintentue par le cordon ombilical non

FIG. 5

Ouverture submédiane de l'espace intermandibulaire au niveau de l'angle du maxillaire inférieur.

Écartement de la trachée. Découpage du cartilage de la jonction pré- et postsphénoïde avec une lancette ophtalmologiste. Ablation à la curette de l'hypophyse.

FIG. 6

Réintroduction de l'embryon dans la poche amniotique. l'utérus.

Fermeture par surjets séparés de l'amnio-chorion et de 

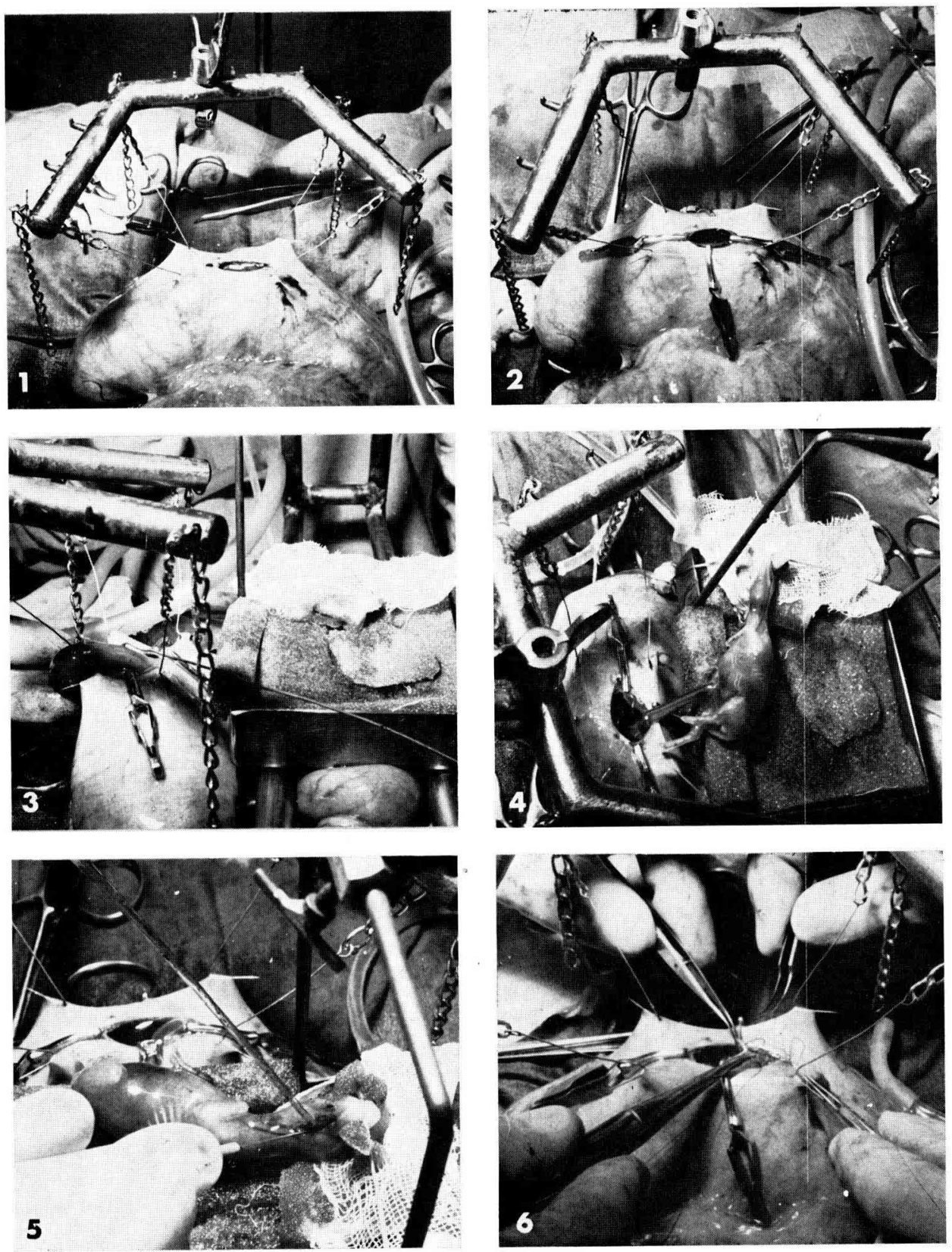


\section{PLANCHE II}

- Ovaires d'embryons de brebis cultivés in vitro el prélevés avant l'apparition de la prophase méiotique :

- moment de prélèvement : 47 jours ;

- temps de culture : 12 jours.

$\mathrm{II}_{\mathbf{a}}: \times 760$.

$\mathrm{II}_{\mathrm{b}}, \mathrm{II}_{\mathrm{c}}$ : figures de prophase méiotique atypique (stade 1 ou stade 2 ). $\times 1.750$.

- Ovaires témoins d'embryons de brebis :

$\mathrm{II}_{\mathrm{d}}$ : de l'âge à la fin de la culture $=60$ jours. $\times 760$.

$I_{e}$ : figures de prophase méiotique typique; leptotène et zygotène dans un ovaire de 60 jours. $\times 1.750$.

- Ovaires d'embryons de brebis hypophysectomisés à 49 jours et prélevés 11 jours plus tard:

II $I_{f}$ : figures de prophase méiotique normale : leptotène et zygotène. $\times 1.750$.

La différence de structure entre un ovaire cultivé in vilro pendant 12 jours $\left(\mathrm{II}_{\mathrm{a}}\right)$ avec un ovaire témoin de 60 jours ( $\left(\mathrm{I}_{\mathrm{d}}\right)$ est flagrante.

Le stade 1 des figures de la prophase méiotique des ovaires cultivés in vitro ( $\left(\mathrm{I}_{\mathrm{b}}\right.$ et $\mathrm{II}_{\mathrm{c}}$ ) est proche du stade leptotène normal (II $)$ mais le stade 2 ne ressemble pas au stade zygotène normal (II ). Chez les embryons hypophysectomisés, ces 2 stades ne sont pas morphologiquement anormaux au niveau d'observation considéré ici $\left(I_{\mathrm{f}}\right)$. 
- 18.56 .58 ). - - 19

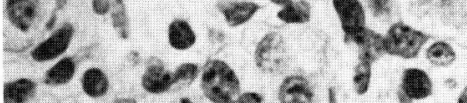
5 ros. 5.0

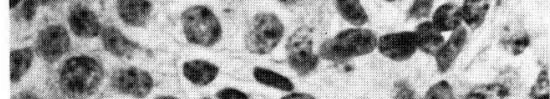

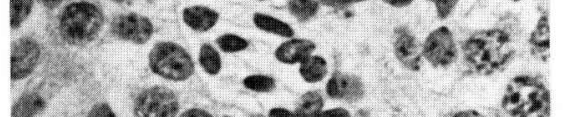
$-4 c^{-2} .8^{\circ}$

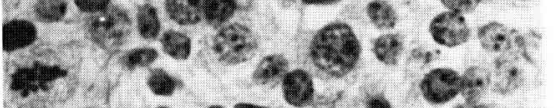
$0.200^{\circ}$

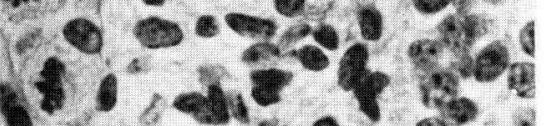
II 2 .
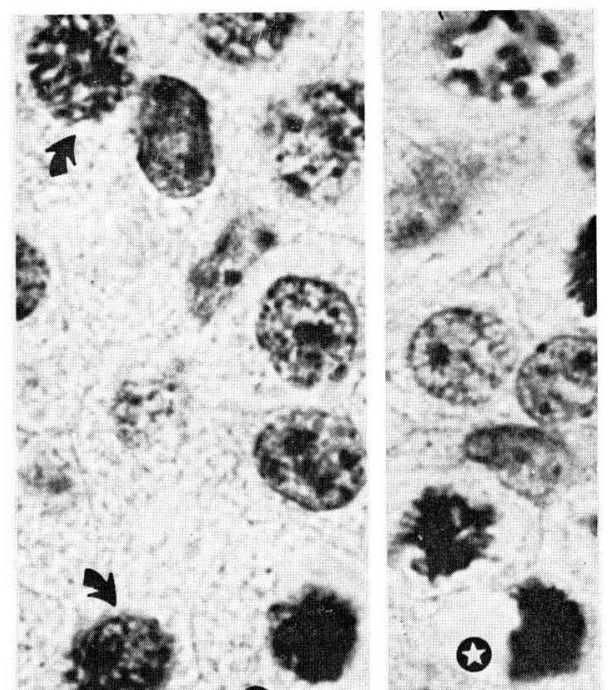
IIb 2 :and

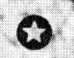
늘
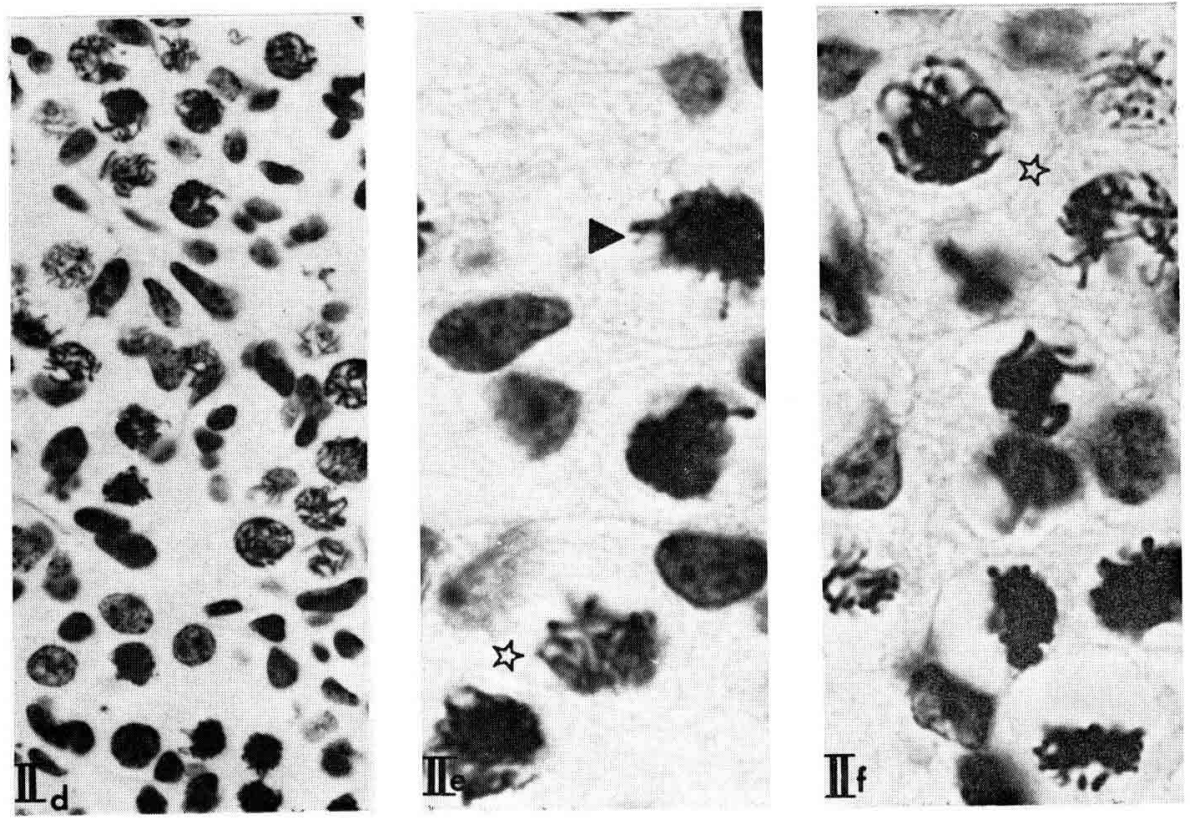


\section{PLANGHE III}

- Ovaires d'embryons de brebis cultivés in vitro prélevés après l'apparition de la prophase méiotique :

- moment du prélèvement : 56 jours ;

- temps de culture : 8 jours.

III $_{\mathbf{a}}: \times 760$.

$\mathrm{III}_{\mathrm{b}}: \times 1.750$.

- Ovaires témoins d'embryons dc brebis :

III $_{c}$ : à l'âge correspondant à la fin de la culture $=65$ jours. $\times 760$.

III $_{d}$ : figures de prophase méiotique typiques : pachytène diplotène dans un ovaire de 65 jours. $\times 1.750$.

- Ovaires d'embryons de brebis hypophysectomisé à 48 jours et prélevé 20 jours plus tard :

III $_{e}$ : figures du prophase méiotique normales : pachytène diplotène. $\times 1.750$.

$\mathrm{Au}$ moment du prélèvement le $56^{\mathrm{e}}$ jour, il existe dans l'ovaire des figures leptotène et zygotène qui évoluent en pachytène et diplotène (III $\left.I_{a}\right)$. Après 8 jours de culture tous les stades de la prophase méiotique sont présents comme dans l'ovaire d'âge correspondant à $56+8$ jours de culture, c'est-à-dire 65 jours (III $)$. Mais dans ce dernier ovaire $\left(\mathrm{III}_{c}\right)$ la proportion de stades leptotènes est beaucoup plus élevée que dans celle d'un ovaire de 56 jours mis en culture pendant 8 jours $\left(\mathrm{III}_{\mathrm{a}}\right)$.

Les stades pachytène et diplotène ne sont pas morphologiquement différents après 8 jours de mise en culture (III $\left.I_{b}\right)$ de ceux d'un ovaire témoin de 60 jours $\left(\mathrm{III}_{\mathrm{d}}\right.$ ) ou d'un embryon de 48 jours hypophysectomisé depuis 20 jours (III $)$. 

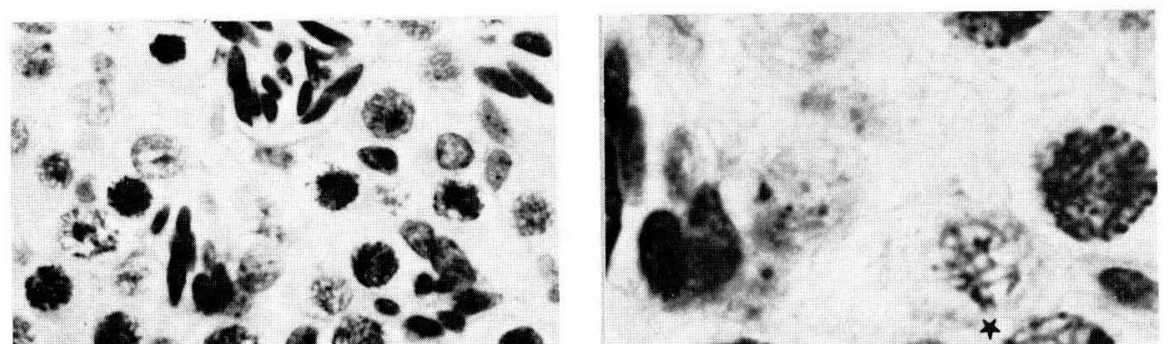

c. 0 6 150 - 0.6 - 8 . - tes $>$

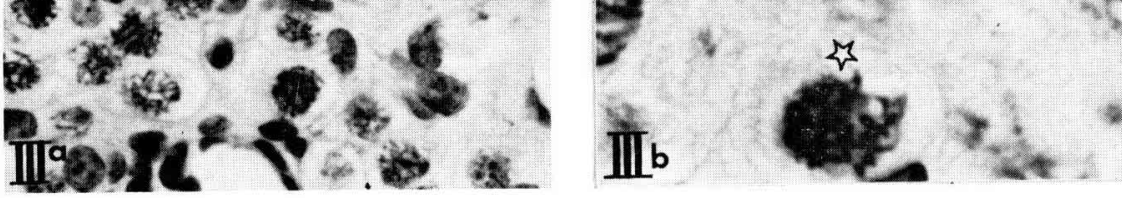

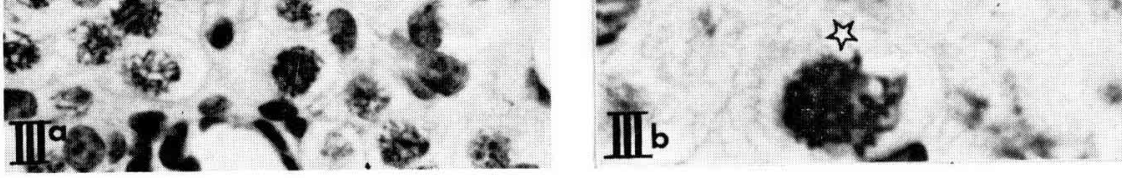

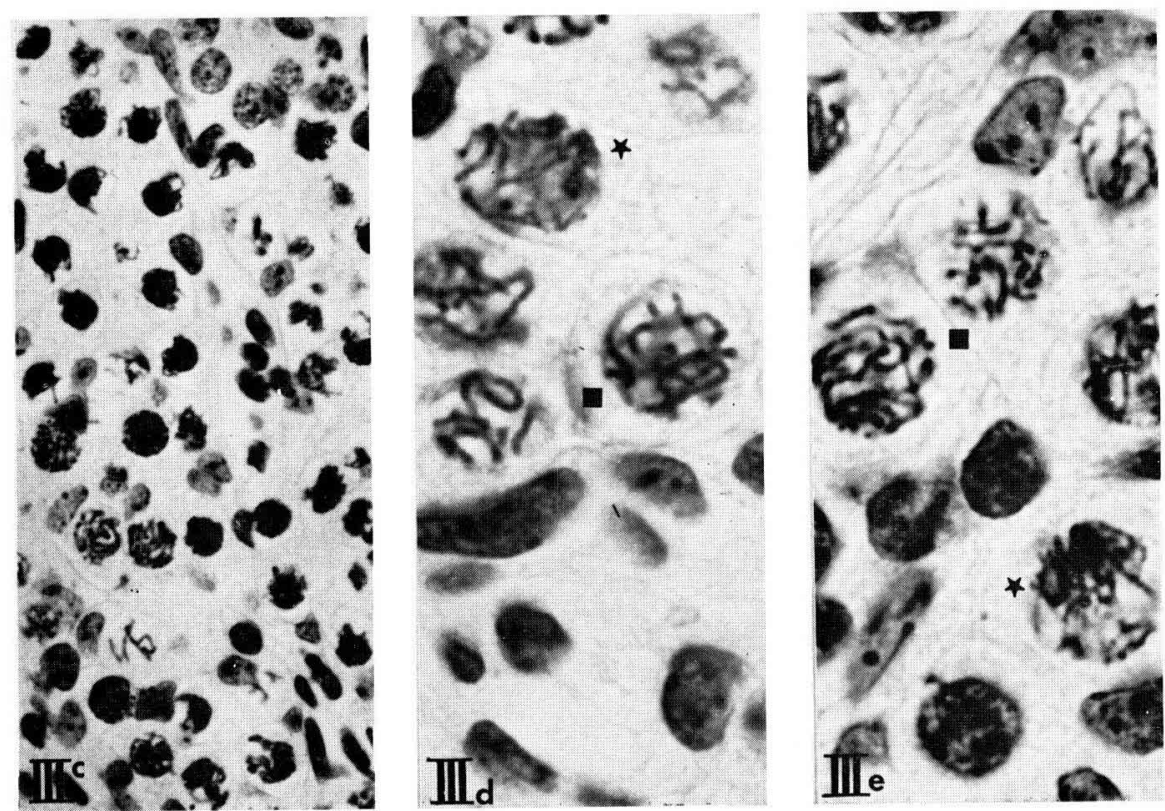


PLANCHE IV

- Ovaire d'embryon de brebis de 47 jours mis en culture pendant 9 jours et greffé pendant 14 jours chez un embryon hôte de 57 jours :

$\mathrm{IV}_{\mathrm{a}}: \times 750$.

$\mathrm{IV}_{\mathrm{b}}: \times 1.750$

- Ovaire témoin d'embryon de brebis de 74 jours :

$\mathrm{IV}_{\mathrm{c}}: \times 760$.

- Ovaire d'embryon de brebis décapité à 47 jours et prélevé 30 jours plus tard :

$I_{\mathbf{d}}: \times 760$.

L'ovaire d'embryon de brebis décapité ( $\left.I V_{d}\right)$ présente une structure identique à celle de l'embryon témoin de 74 jours (IV $V_{c}$ ) caractérisée par l'édification des follicules primordiaux et la présence de nombreuses pycnoses.

Par contre, le greffon $\left(I V_{a}\right)$ a une structure qui correspond plutôt à celle d'un ovaire de 60 jours, ce qui prouve que les cellules ont cessé de se différencier pendant le temps de culture et gue la prophase méiotique est apparue et a évolué jusqu'au stade diplotène dans l'environnement d'un embryon de 57 jours. 
6.

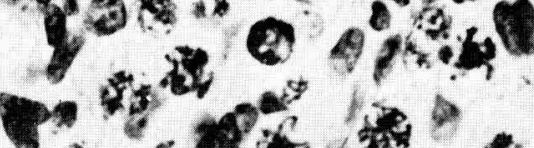

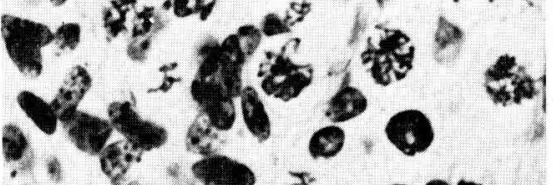

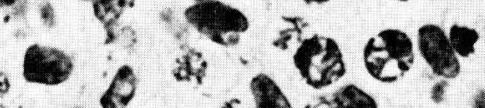
$4 x^{\circ}$ x - 8 a 32 6. 30 $20 \%$ क 3

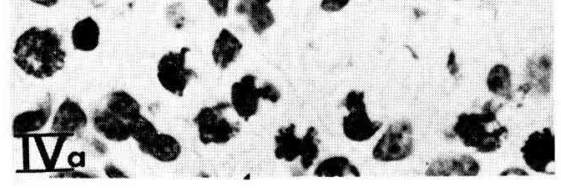

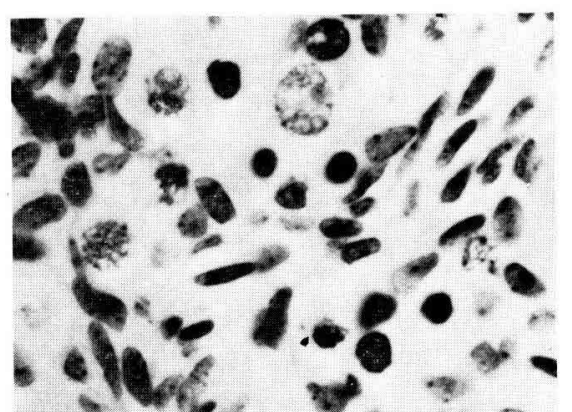
0 (b)

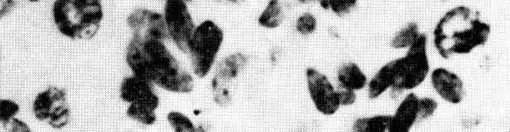
$N^{2}+0^{2}=1$ 更
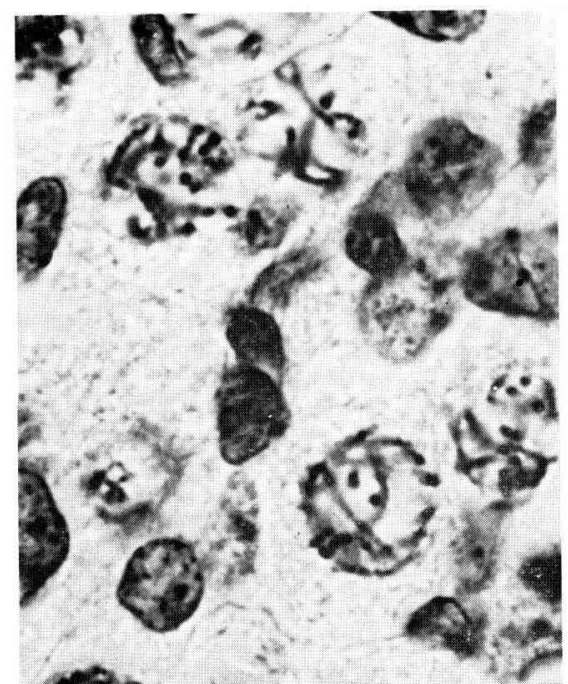

5.5

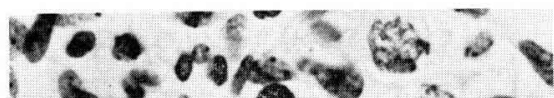
$-50^{2}$ ? (2) 075 $f 0^{-2} 00$ 1 s $4010-20$ - 5 - -0.50 50 s $\therefore=0$

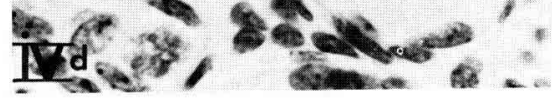

